\title{
The Use of Infliximab to Control Recurrent Cytokine Storms in EBV-Associated Angioimmunoblastic Lymphoma and Hemophagocytic Syndrome
}

\author{
Sameh Gaballa \\ Thomas Jefferson University Hospital \\ Emmanuel Besa \\ Thomas Jefferson University Hospital \\ Onder Alpdogan \\ Thomas Jefferson University Hospital
}

\section{Follow this and additional works at: https://jdc.jefferson.edu/medoncfp \\ Part of the Hematology Commons, and the Oncology Commons Let us know how access to this document benefits you}

\section{Recommended Citation}

Gaballa, Sameh; Besa, Emmanuel; and Alpdogan, Onder, "The Use of Infliximab to Control Recurrent Cytokine Storms in EBV-Associated Angioimmunoblastic Lymphoma and Hemophagocytic Syndrome" (2012). Department of Medical Oncology Faculty Papers. Paper 15. https://jdc.jefferson.edu/medoncfp/15

This Article is brought to you for free and open access by the Jefferson Digital Commons. The Jefferson Digital Commons is a service of Thomas Jefferson University's Center for Teaching and Learning (CTL). The Commons is a showcase for Jefferson books and journals, peer-reviewed scholarly publications, unique historical collections from the University archives, and teaching tools. The Jefferson Digital Commons allows researchers and interested readers anywhere in the world to learn about and keep up to date with Jefferson scholarship. This article has been accepted for inclusion in Department of Medical Oncology Faculty Papers by an authorized administrator of the Jefferson Digital Commons. For more information, please contact: JeffersonDigitalCommons@jefferson.edu. 


\title{
As submitted to:
}

\section{Blood}

\section{And later published as:}

\section{The Use of Infliximab to Control Recurrent Cytokine Storms in EBV-Associated Angioimmunoblastic Lymphoma and Hemophagocytic Syndrome}

\author{
Blood (ASH Annual Meeting Abstracts) 2012 120: Abstract 4887
}

December 8-11, 2012-Georgia World Congress Center, Atlanta GA.

\author{
Sameh Gaballa, $\mathrm{MD}^{1}$, Emmanuel C. Besa, $\mathrm{MD}^{2}$ and Onder Alpdogan, $\mathrm{MD}^{3}$ \\ ${ }^{1}$ Hematology and Medical Oncology, Thomas Jefferson University Hospital, Philadelphia, PA, \\ USA, \\ ${ }^{2}$ Kimmel Cancer Center, Thomas Jefferson University, Philadelphia, PA, USA, \\ ${ }^{3}$ Medical Oncology, Kimmel Cancer Center, Thomas Jefferson University, Philadelphia, PA, \\ USA
}

\begin{abstract}
4887
Introduction: Chronic active Epstein-Barr virus infection (CAEBV) has been implicated in several diseases including hemophagocytic lymphohistiocytosis (EBV-HLH) and lymphomas including Angioimmunoblastic T cell lymphoma. The exact mechanism by which EBV infection causes these complications is currently not well understood. EBV-HLH is a syndrome in which T-cells, NK cells and macrophages are aberrantly activated. Cytokine storms play a major role in cellular damage and organ dysfunction. In the event that the body is unable to clear the EBV viremia, dysregulated T, NK cells and macrophages continue to release cytokines leading to the accumulation of lymphohistiocytic infiltrates into organs and organ damage. Cytokine storms can lead to death from multi-organ failure. During a cytokine storm, levels of several cytokines are elevated including TNF-a, IFN-g, sCD25, IL-12, IL-1, IL-10 and IL-18. ${ }^{1-3}$ Current lines of therapy of EBV-HLH include steroids, etoposide, cyclosporine, ATG and hematopoietic stem cell transplantation. We report successfully controlling frequent cytokine storms in a patient with EBV induced angioimmunoblastic lymphoma and HLH with weekly infliximab after failure to do so with chemotherapy (CHOP-E; cyclophosphamide, daunorubicin, vincristine, prednisone, etoposide), rituximab and bortezomib.
\end{abstract}

Case: This is a 35 year old African American male with a long history of adenopathy who presented with autoimmune hemolytic anemia, autoimmune thrombocytopenia (ITP), neutropenia with fever and hypotension. Work up revealed persistent EBV viremia and the lymph node biopsy revealed Angioimmunoblastic T cell lymphoma. High dose dexamethasone and Intravenous immunoglobulins (IVIG) failed to control his hemolysis and ITP. Rituximab and bortezomib successfully controlled his autoimmune hemolysis and thrombocytopenia. However, cytokine storm episodes, characterized by high fevers, hypotension and respiratory distress, 
continued every 1-2 weeks requiring ICU admissions. Chemotherapy (CHOP-E), for his underlying lymphoma, followed by etoposide/steroids (HLH-94 protocol) were also ineffective at controlling his cytokine storms. Considering that he had high levels of TNF-a, infliximab was started in an attempt to control dysregulated macrophages and T-cells, and was able to successfully prevent the cytokine storms. High levels of IL-6, soluble IL-2 receptor and TNF-a were all detected during cytokine storm episodes. The patient is currently getting prepared for an allogeneic stem cell transplant.

Discussion: We report successful control of EBV-HLH related cytokine storms, guided by TNFa levels, with weekly infliximab (Fig 1). Hypercytokinemia is believed to result from dysregulated T cells, NK cells and macrophages as a result of failure to control the EBV viremia. In this case a TNF-a inhibitor (infliximab) was used to control dysregulated macrophages, $\mathrm{T}$ and NK cells and block further propagation of inflammatory cytokines. Initially infliximab was initiated on a once every 2 week schedule, however, this failed to prevent cytokine storms with high TNF-a levels. However, weekly dosing of infliximab successfully prevented cytokine storms and controlled his TNF-a levels (Fig 1). Moreover, an attempt to taper off the weekly infliximab and etoposide resulted in relapse of his symptoms and a sharp rise in ferritin levels, a marker for HLH activity (Fig 2). This suggests that infliximab might be an effective therapy in preventing cytokine storms related to EBV-HLH and further studies are warranted.

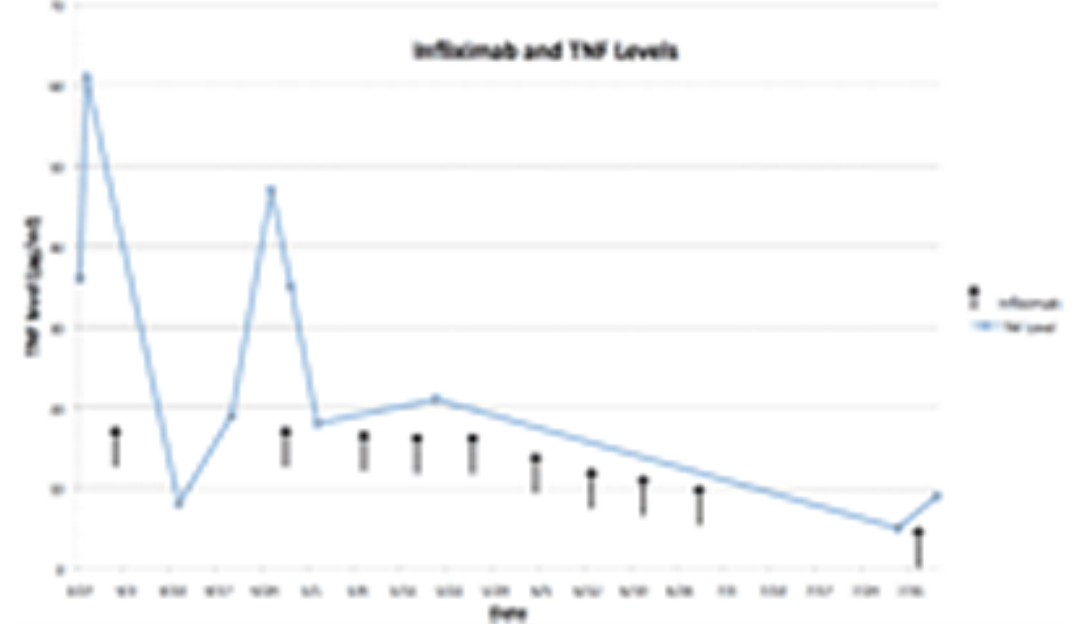

\section{Fig 1. Elevated levels of TNF-a Levels were successfully controlled with weekly infliximab which correlated with clinical improvement and prevention of cytokine storms}




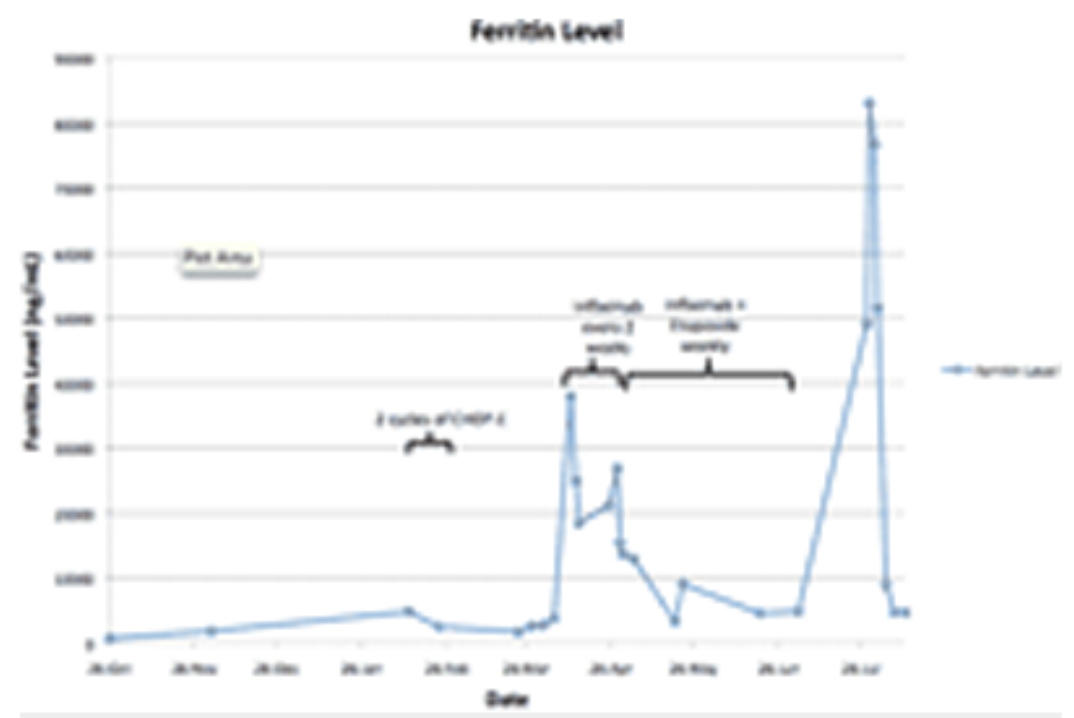

Fig 2. Ferritin levels were used to monitor the activity of the hemophagocytic syndrome. After initiation of weekly infliximab, guided by TNF-a levels, the ferritin level remained low with clinical improvement. A trial of tapering the infliximab and etoposide resulted in a relapse of symptoms and a sharp rise in ferritin level. 